\title{
MODERN SOCIAL CONDITIONS AND THE NEED FOR INTEGRATED SOCIAL REGULATIONS
}

\author{
by Dr. Özer OZANKAYA \\ Assoc. Prof. of Sociology \\ Faculty of Political Sciences \\ University of Ankara
}

\section{INTRODUCTION}

In modern industrial societies where very dense interrelations and intrarelations of very many sonts predominate any error in the choices made by either Governments or people is liable to cause serious damages. In that social context in which the field of public responsibility is enormously extended and the criteria of public interest need to be defined in a great detail the concept of "scientifically regulated society» has begun to receive increasing acceptance.

Paralleling the evolution and growth of this need for scientific methods and means of social regulation is the development of a 'social science' concept bringing ever more to the feroground its own role of giving directions to the policy makers and administration, shedding lights on their way and enabling them to act with foresight. Under the pressure of this need there emerges a growing agreement among social scientists with respect to the basic problems of the present-day social sciences and to their solutions.

\section{The Concept of 'Science' in Modern Society}

Like many other concepts that of 'science', too, has been undergoing through a change process reflecting the pursuing of democratic ideals and principles in actual social life with ever greater efficiency. Indeed within the definition of science in mo- 
dern society the following elements are occupying the chief place: 'a system of knowledge providing mankind 1) with an explanation as to the regularities in the evolution, operation and change of both his social as well as natural environment and his place in that environment and 2) with reliable and valid methods and means to enable him to influence that environment in ever greater extent in the way of arriving at those millenary democratic idealis of freedom, equality, public interest... In the face of modern society's objective conditions making necessary that masses of people decide themselves -and not the "invisible hand" of the so-called free market system, nor a central bureaucracy-about their own fate, science is valued by people in direct proportion as to the degree to which it is oriented toward these ideals and is successful in arriving at them. The basic methodological issues of such a science, namely levels of analysis, time dimension of analysis and operational concepts and frames of analysis have acquired prime importance. In my opinion the crisis situation in present-day societies as well as in the social sciences themselves is, to a great extent, due to the still nonsufficient consideration paid to this aspeat of the problems.

\section{Modern Soclety}

In modern society the scale of relations has considerably grown; the need for organization and co-ordination has turned into a necessity and a change in any part of the social system is liable to cause reciprocal changes in almost all of its other parts. Life in such a society goes on, in considerable proportions, in metropolices and big settlements, within large-scale production units and organizations; all social activities from production to education, social security, employment, housing, leisure-time activities... are carried out within bureaucratized institutions. Modern society has evolved into a public-service society. TV, radio, press, sattelite communication and mass transportation webs form the blood circulation system of such a society.

In accordance with the great increase in the interactions between various social groups, in the extent and influence of the "public interest" considerations, and in the activities of the public administration, the dissemination, among the people, of reliable and valid knowledge about the social system and its various aspects has become a necessity. The need that the citizens in general should be equipped with the kind of knowledge, values, attitudes and skills 
which would enable them to panticipate efficiently in the running of the public affains has become ever more imposing. Within these conditions of modern society people have become aware of the fact that it is not enough only to understand the world but that what is needed is the capacity to change it. As Karl Mannheim has observed, «it has become an obligation to put into practice the knowledge related to every knowable aspect of social life. ${ }^{1}$.

These characteristios of modern society are the indications of the fact that its objective conditions both necessitate and make possible the elimination of social inequalities and the increasing realization of democratic ideals. What else is the science but the product of necessities and possibilities?

But while the conditions of modern society described above necessitate increasingly regulation of production and distribution in such a way as to realize to the greatest extent possible the democratic principles, practices proper to the periods of ignorance where the powerful is regarded to be always night cause the crisis situations by preventing the meeting of this necessity. On the one hand there are wastes of resources of the market economy system oriented not to provide service and utility but rather to a "consumption" no matter how and where. The content of production, the services of education, health, social security, housing and envinonment, recreations... all are very deeply influenced and rendered unproductive by this principle of "consumption». In fact the contradiction between the rationality in the partial practices (micro planning) and the irrationality in the decisions at the global level is becoming more and more evident. But on the other hand the problem of developing the methods and means of a democratic general planning is still unsolved. A centralized general planning has led in practice up to now to bureaucratic dictatorships and thus has not been successful in alleviating the alienation of man. As Raymond Williams has put it "democratic planning is an easy phrase to pronounce, but no one actually knows how it would work. Nevertheless, the difficulties of general planning can not be an excuse for not doing any planning at all, as the problems and needs do not

(1) Karl Mannheim, Ideology ahd Utopia, Routledge and Kegan-Paul, 1936, pp. 169-170. Also the chapter on "The Prospects of Scientific Politics: The Relationship Between Social Theory and Political Practice» pp. 97-171. 
disappear because it is difficult to solve and meet them; on the contrary, they become more acute. $\aleph^{2}$.

Thus the most efficient solutions to these critical problems of modern society are to be found in the development, in the masses of people, of a participant democratic political culture, and in the growth of the number of scientists, technocrats and politicians inspired by the democratic ideals and principles.

\section{EMERGING TRENDS IN SOCIAL REGULATIONS}

Social regulation is actually practiced in varying degrees in every society at two different levels, with or without a formal planning body ${ }^{3}$ : it is, on the one hand considered as a complement to economic planning and defined with reference to the fields or sectors that it covers; it is becoming, on the other hand of an all embracing character, because of the growing need for expressing and mastering the broad objectives and main choices of society. Thus it is becoming clear that social objectives should not be seen as a mere addendum to economic growth, but that they must be built into the very global planning model itself.

The problem of achieving an integration of these two levels of preparation of plans has assumed growing importance and the increasing diversification and complexity of present-day societies give new dimensions to the problem of integration.

The field covered by planning is expanding; the preoccupations of the decision making centers - particularly those of public authorities - are becoming more diversified and include growing number of global and sectoral social problems.

The time dimension is assuming increasing importance and the long term approach must be considered and dealt with in the policies and plans.

The traditional sectoral problems of social regulation such as those of education, housing, health, a.s.o. are assuming new forms because of the interconnections between the policies applied to each

(2) Raymond Williams, The Long Revolution, Pengouin Books, 1961, p. 321.

(3) More on these emerging trends in U. N. Economic Comission for Europe, Approaches and Methods Used in Long-Term Social Planning, N. Y. 1973. Particulary pp. 3-14. 
of them as well as to other sectors of society. Therefore planners and decision-makens along with social scientists are paying increasing attention to such global or intersectoral problems as those arising in developing countries from the unequal nature of international exchange (i. e, regional underdevelopment, false urbanization, unemployment and underemployment) or more generally the relative shares of public and private consumption, the distribution of income and purchasing power, man's relationship to his environment etc.

In view of this dual evolution of social planning - with respect to its content and its time dimension - the problem of developing methods for achieving better integration in the planning process, that is, at the research, analysis, planning and policy levels. The establishment of a hierarchy of needs, ends and means (vertical integration), the establishment of explicit relations between needs, ends and means (horizontal integration), and the articulation of different planning periods ranging from one-year, to medium-trem, to long-term spans (integration in time); the achieving of this integration at national (including international relations), regional and local levels, all depend in the first place upon developing valid methods of research and analysis.

Let us take a look at the underlining ideas of the Social Welfare concept : it mearis provision of employment opportunities, easy access to jobs, cocupational safety and security, prevision of establishing a bridge between the facts of micro and macro "minimum» income for the people when they are unable to earn; protection against inflation; preventive health measures as well as medical treatment suited to the needs; adequate and balanced nutrition of all society; education and training opportunities in equality according to the individuals' ability, capacity and age; correcting situations broght about by the structural failures of the market system such as accelarating (and in developing countries false) urbanization, environment deterioration, regional underdevelopment, unequal income distribution, poverty, economic crises, etc. Clearly, the ideal of Social Welfare requires the formation of such socio-economic structures and the promotion of such developments in them that all individuals get proper chances to develop economically, socially, culturally. All of these have fundamental methodological implications for the analysis, research, planning and policy aspects of a Social Welfare system. 


\section{BASIC METHODOLOGICAL ISSUES OF THE RESEARCH AND ANALYSIS FOR SOCIAL REGULATION}

In the following paragraphs we are going to summerize these implications and to elaborate on the emerging methodological trends with reference to meet the need for an integrated social regulation.

In view of the above mentioned considerations:

1) The phenomenon of public administration is no more viewed from a mere legal point of view, but is increasingly understood as a social onganization and process,

2) The serious shortcomings of such an abstract definition as «the public administration looks after and takes care of the public interest» are clearly noticed. In fact, in a social context where major class inequalities predominate what is meant by the expression "public interest" is very often the interest of the dominant social strata.

3) The indicators of the development of such a consciousness lie in the fact that, in order to arrive at a more adequate explanation of social reality and to determine reliable ways and means of realizing the democratic principles the followings are considered necessary:

- All major elements of the social structure, among them the public administration which is one of the main responsible institutions to formulate and carry out development and welfare programs, should be analysed not only in terms of their internal units but also in terms of their respective place within the global social system.

- The interrelations and operations of these elements should be studied not only at one particular point in time, but also through the process of their formation, operation and change with the purpose of discovering and mastering the regularities in this process.

- Valid concepts and operational frames of analysis are needed to be developed for such an approach.

In other words social scientists are becoming aware of the failure of micro-sociology and of the possible positive contributions of macro-sociology - which has shown most advanced in historical materialism - to meet the need of the present-day society for democratization. However the fact that historical materialism has 
limited its concern mainly with the reconstruction of socio-economic schemas, with the classification and typification of historical periods has kept it from small-and middle-size explanation efforts and thus from making use of micro-analysis in co-ordination with macro theories. Such an approach would give it the chance of testing itself as a theory and getting enriched with empirical evidence.

This is, in short, in my view the real character of the methodological orientation required from the social sciences by the objective conditions of modern society. In the following pages this orientation will be reviewed in more detail.

\section{A. MICRO AND MACRO-LEVEL ANALYSIS}

During the sixties and seventies micro-sociology has been widely criticized a) for limiting itself to the description of social life within such small groups as family, peer-groups, work-place, schools, hospitals, brigades, prisons... and according to the scheme of "Norms - Status - Roles»; b) for not having developed a general theory of society to explain the separate existence of the global social system nor even the place which individual units occupy within this system; and c) for the consequent overdivision of the social sciences into numerous branches and the harmful isolation of empirical research from theoretical considerations. Along with the objective conditions of modern society necessitating the mastering of the social environment in order to put into practice the democratic principles of freedom, equality, public interest (to say it in a phrase the principle of "man, the ultimate value») social scientists have been acknowledging the need for a general theory of society and for the oo-ordination of micro research with macro analysis ${ }^{4}$. One example of such considerations lies in the increasingly felt need to explain the place of public administration, the executive agent of the political power, within the global social system. In this way the Marxian analysis of public administration is referred to in widening circles and as I have pointed out above, the fact is reckoned that in a class society it is basically in the ser-

(4) For instance R. Blackburn (ed.) Ideology in Social Science, Fontana, 1972; A. Gouldner, Coming Crisis in Western Sociology, Heinemann 1970; Michel Crozier, La Société bloquée, Seuil, 1975; Maurice Duverger, Méthodes des sciences sociales, P.U.F., 1959. 
vice of the dominant strata ${ }^{5}$. Particularly the basic factors of the failure of social welfare practices which, by definition, aim at correcting situations brought about by the structural characteristics of the market system can only be understood through a macro-level analysis.

But at the same times it is reminded that along with this macro-level analysys there still remain an essential need for micro analysis : for instance it is pointed out that the determining factor of public administration is not only its particular role in the class struggle, but also its internal components have their share in posing bottlenecks and causing disorderliness in its operation. It is also suggested that only through micno-level analysis co-ordinated with macro-level explanations can we approach and understand such basic parts of any administration as the internal structure of the organization, the formal and informal hierarchies in it, and their operation, the role of the legal norms, power relations, the formation of internal monopolies, division of the services into separate compartments, disputes among the personnel, etc. ${ }^{6}$.

The problem here is that of establishing the connection between the two levels of analysis, namely, to conduct micro research with macro-level explanations in mind. For the solution of this problem it is necessary to arrive at a valid conception on the general nature of culture and social institutions, a conception which underlines the following elements in the definition of each:

Culture is the conceptual expression of the system formed by the material things together with the corresponding knowledge, arts, skills, values, beliefs and attitudes, created by a people in the historical process of social production. It shows the level of progress in technology, production, education, science, literature and fine arts, the degree of man's control over his natural and social environment. The spiritual elements of this system evolve after the material elements show a minimum degree of develop-

(5) Danièle Loschak, «La science administrative: quelle science? quelle administration?" Revue Internationale des Sciences Administratives vol. XLI, No. 3, pp. 238-252. Loschak, too, emphasizes in this article the importance of the levels, time-dimension, and frames of analysis for a scientific explanation of public administration. I have benefited very largely from this article.

(6) For instance Michel Crozier, Le phénomène bureaucratique, Seuil 1975; La Sociétée bloquée, Seuil, 1975; Lucien Nizard, Changement social et appareil d'Etat, in Loschak, op. cit. 
ment, and form a system of norms, actions and symbols. The dominant material and spiritual elements of a culture form together a relatively homogenious, harmonious and co-ordinated whole called the "cultural system».

Social institutions are those components of social structure formed by relatively homogenious and co-ordinated ideas, beliefs, traditions and behaviour patterns as well as material elements, showing a relative continuity. Social institutions, too, form all together a relatively harmonious, co - ordinated whole called the "social system». In fact they are devised by that system to underline it and to contribute to its continuity.,

Such conceptions about culture and social institutions provide us with the possibility of observing the norms and regularities of operation of the global social system at the levels of various social groups within it. When applied to the field of administration this approach would enable us to see that «bureaucracy» is a "cultural» phenomenon, as every bureaucratic system shows characteristics peculiar to the global societal system and that there exist factors making for the adjustment of the functioning of public administration to that of the social system in general. Viewed from this standpoint it would be very easy to show the profound similarities among the systems of, for instance, education, health, housing, human relations in the work place... This systemic approach to culture enables us to show the overlapping between the administrative structure and the structure of culture and the interdependencies between various sectors of social life. Hence the concept of "total development» and the inadequacy of those partial concepts of development such as economic development, economic growth, industrial development... This approach could prove fruitful, in my opinion, in the analysis of the social welfare policies and administration as well, as it would enable us to think in more concrete ways about the formation and limits of any onganization, to show the degree of autonomy of the fact of organization, and to clarify the role of cultural elements in the national society as a whole ${ }^{7}$. The study of organizations as systems provides us with the possibility of establishing a bridge between the facts of micro and macrosociology. Starting from the analysis of a local welfare organization, for instance, we can shift to the level of State administrative system, since the local or sectoral equilibrium itself results from the central power structure and is oriented towards streng-

(7) Michel Crozier, La société bloquée, op. cit. 
thening and perpetuating that strucure and tuhs serving as an indispensable buffer mechanism. ${ }^{8}$. It also becomes clear that many of the internal characteristics of an administrative system can only be understood through an analysis of the society as a whole, since there is a direct relationship between these internal characteristios and what the social system requires from that organization".

More concretely, if we agree that the concept of Social Welfare assumes :

- The concentration of economic power at the hands of the masses of people earning their living through their own labour (as against at the hands of a capitalist class or at those of the State);

- the increase of the political power of the masses of people;

- the decrease of the discrepancy between the governing and the governed,

then we can also agree that it requires, on the one hand, the creation of a public administration which is not a mere servant of the Government and, on the other hand, the realization of the freedom of education. Planning and policy-making for such a social welfare concept must be based on the integration of macro- and microlevel analysis.

\section{B) TIME - DIMENSION : HISTORICAL AND SYNCHRONIC ANALYSIS}

Another requirement for a scientific analysis to be operational (i.e. to discover regularities) is to consider social institutions not only in their operation and interrelations at one point in time, but also in their evolution and change through time. The value of the historical analysis in arriving at more reliable and valid explanations is being acknowledged by the social scientists.

\section{The Indispensable Contributions of the Historical Analysis :}

Many social scientist, neventheless, Structuralists in particular, still prefer to limit their concerns with the description of social

(8) Alain Darbel et Dominique Schnapper, Morphologie de la haute administration française, in Loschak, op. cit.

(9) Pierre Grémion, «Introduction à une étude politico-administrative» Sociologie du Travail, No. 1, 1970. in Loschak, op. cit. 
structure's and neglect studying the process of their formation and evolution - this, with the worn out claim that social facts are not repeated identically and through affecting them history prevents us from constructing models - as if all physical phenomena were repeated identically or all of the individuals of a biological species were completely the same...

It is impossible, however, to understand the historical social prosesses through such a static, formalistic, a-historical approach, because each phenomenon can only be explained within a historical process wider than itself. "History has an importance similar to that of geology $»^{10}$ for the understanding and regulation of social life. As it is known, for instance, socio-economic development means well-balanced and more or less simultaneous advances in all of the major fields of the social life from production to science and arts, education, health, social solidarity, democratic political culture... Socio-economic activities centering around only few number of products (e.g. banana, ore and other raw materials), concentrating only in limited geographical parts of the country (seaports, raw material extraction or production areas) do not lead to «development» proper, but rather to socio-economic-cultural disorganizations and deformations. As it is also known all of the Third World countries have witnessed - and they still do today- not a development but rather a socio-economic-cultural deformation and disorganization process. This situation can only be explained through the historical analysis of colonialism and imperialism ${ }^{11}$.

\section{The Value of the Synchronic Analysis}

As the reality is always concrete, no explanation overlooking the «local» factors can possibly hope to be universally valid.

The synchronic analysis is based on the observation that events are not only the outcome of the factors preceding them, but also that of being the functional parts of a structure, since there exists an interdependency between synchronic social events. This interdependency should not be considered as an impediment to discern determining factors and to establish a hierarchy of importance among the factors. Synchronic analysis on these lines contribute zreatly to our understanding of the system, function and structure.

(10) Pierre Legendre, Histoire de l'administration, P.U.F., 1968, in Loschak. op. cit.

11) This is the dominant conclusion of the greatest part of the literature on underdevelopment. 
The Ideal Type method developed by the German sociologist Max Weber is one such method that enables us to arrive at an advanced level of formalization and conceptualization when the task of pointing to the determining factor(s) and to the hierarchy of importance among them is not neglected.

In the field of public administration where the social sciences are most needed to be operational the synchronic analysis of the interrelations between the administrative system and its economic, political, cultural... environment are increasingly becoming a point of reference. To begin with, the structural interrelations between the distribution of, let us say, income or educational, health, housing... opportunities and the nature of the ownership over the means of production have to be assessed. Then comes a second order of interrelations such as those between environment problems or regional under-development and the structural characteristics of urbanization, industrialization, etc.

As the above mentioned examples clearly show historical and synchronic analysis are together needed at both macro and micro levels of explanation.. An example of the simultaneous use of historical and synchronic analysis at the macro level is provided by historical materialism. Through explaining the structural interrelations between what it calls production forces, production relations and ideological structures formed on the basis of the first two, this theory shows social interactions and the hierarchy of importance among various factors determining them (: synchronic analysis). It takes into consideration, on the other hand, fact of evolution which it holds to be dialectical in nature operating through a conflict process and aiming at the elimination of social inequalities (: historical analysis). Besides, by holding that historical evolution is independent from the individual wills and controles and that it is a natural, objective and predictable process this theory provides a consistent explanatory scheme.

The example, at the micro level, of the simultaneous use of historical and synchronic analysis is found in the genetical structuralism approach. Based on a synthesis between historical materialism and structuralism, this theory is on the one hand oriented to show the existence of regular and therefore explicable relations among the conditions of any fact studied and, on the other hand, it is based on the assumption that reality is never static and that its state at any given point in time is not "structure», but a mixture of "structuration» and "disstructuration» processes. Considering 
that every equilibrium is temporary this approach sees it as the necessary dimension of the scientific explanation to show how this equilibrium is formed.

\section{C) CONCEPTUALIZATIONS AND FORMATION OF OPERA- TIONAL FRAMES OF ANALYSIS}

To understand the reality in its changing nature its substance must be conveived. As the appearance and substance of a phenomenon do not immediately adjust to one another it becomes necessary to go beyond the form in which it appears and to catch the difference between the perception and conceptualization in relation to it. Only through this way can it be shown that what makes history are the regularities and that every regularity has its own period when it is effective. As Georges Gurvitch has observed every branoh of science constructs, more or less artificially, operational frames of analysis in order to render its subject of study amenable to the explanation and verification processes.

The nonsufficient consideration paid by social scientists to the need of categorization and formalization of the social reality and the tendency to limit the scientific efforts by mere empiricai descriptions deprive us from elements necessary for the explanation of reality. In fact the objective conditions of modern society increasingly require the clarification of the webs of interrelations which are beyond the appearance and therefore not amenable to immediate understanding. For this reason the subject-matter to be studied has often to be mentally reconstructed and this depends upon developing suitable concepts which both enable us to analyse the reality in its complexity and are, in order to serve this purpose, loaded with the ideology of democracy. For instance Lucien Nizard expresses this need felt in modern society when he complains in his Changement Social et Appareil d'Etat against the uses of such concepts as "public interest», "public - private differentiation", "public service» in the ways to justify an undemocratic social order and to condition individuals to that onder and when he points to the necessity of a previous critical examination of such concepts in order to determine the ideological function they accomplish and the real social practices they reflect. 


\section{SUMMARY}

The objective conditions of modern society increasingly bring forward the necessity for the social sciences to abide with such methodological principles as the simultaneous use of micro and macro analysis, historical and synchronic analysis and development of concepts and frames of analysis suitable to enable social sciences to serve democratic ideals and principles.

The chief problem of modern society lies, in my view, in how to realize rationality at the macro level. Therefore a social science can not possibly be satisfying by being oriented only towards understanding - let alone only to describing - the social reality. Instead, what is needed is a social science capable of changing that environment in the direction of democratic ideals of freedom, equality, "man, the ultimate value». 